\title{
INTERACTION STUDY: THE EFFECT OF ORTHOSIPHON STAMINEUS EXTRACT ON HUMAN CYTOCHROME P450
}

\begin{abstract}
1Dept of Pharmacology and Clinical Pharmacy, Faculty of Pharmacy, Gadjah Mada University, Skip Utara, 55281, Yogyakarta, Indonesia

${ }^{2}$ Centre for Drug Research, Universiti Sains Malaysia, 11800, Penang, Malaysia
\end{abstract}

Submitted: 05-05-2014

Revised: 07-08-2014

Accepted: 21-09-2014

*Corresponding author

Purwantiningsih

Email :

purwanti_n004@yahoo.com

\author{
Purwantiningsih $^{1} *$, Abas $\mathrm{Hj}$ Hussin ${ }^{2}$
}

\begin{abstract}
Herbal remedies are often used concomitantly with prescribed medication, which leads to an increase in the potential of herb-drug interactions. Orthosiphon stamineus is one of the popular herbal preparations that is traditionally used, especially as a diuretic or for the elimination of kidney stones. The inhibitory effect of $O$. stamineus extract on human cytochrome P450 isoforms, namely CYP1A2, CYP3A4, CYP2C9 and CYP2D6, has been determined using luminescent methods. The final concentrations of 0 . stamineus extract tested were $0.01,0.1,1$, 10,100 and $1000 \mu \mathrm{g} / \mathrm{mL}$. IC 50 value was used to assess the modulation potencies for each CYP isoform. The extract showed a moderate inhibition towards CYP2C9 with the $\mathrm{IC}_{50}$ of $20.12 \mu \mathrm{g} / \mathrm{mL}$ and showed $\mathrm{IC}_{50}$ of $49.90,89.24$ and $97.82 \mu \mathrm{g} / \mathrm{mL}$ for CYP1A2, CYP2D6 and CYP3A4, respectively. These data suggest that $O$. stamineus extract may potentiate the herb-drug interaction via CYP inhibition.
\end{abstract}

Key words: Orthosiphon stamineus, inhibitory effect, CYP isoform

\section{INTRODUCTION}

Herbal preparations have been widely used in the world and the market has been rapidly growing in recent years. Orthosiphon stamineus Benth, belonging to the family Lamiceae, is one of the most popular medicinal plants in Southeast Asia, including Indonesia and Malaysia. O. stamineus is locally known as Misai Kucing or remujung, and has received great attention from researchers. The plant is used as an alternative medicine in Malaysia and has also been sold as a dietary supplement in recent years (Wiart, 2002). In many European countries, $O$. stamineus is consumed as a herbal tea to promote health due to its high antioxidant properties (Indubala and $\mathrm{Ng}, 2000$ ).

O. stamineus contains several chemically active constituents; one of the most important classes of compounds is the phenolic group. Some researchers have isolated many phenolic compounds including lipophilic flavones, flavonol glycosides, and caffeic acid derivatives, such as 2,3-dicaffeoyltartaric acid and rosmarinic acid, which have been identified and quantified by High Performance Liquid Chromatography (Sumaryono et al., 1991). O. stamineus leaves contain polymethoxylated flavones, sinensetin, tetramethylscutellarein and 30-hydroxy5,6,7,40-tetramethoxyflavone, as reported by Pietta et al. (1998). Other researchers (Tezuka et al., 2000) found the chemical constituents of $O$. stamineus to include caffeic acid derivatives, diterpene esters, triterpene saponins, flavonoids, antioxidants and volatile oil.

A number of interaction studies of $O$. Stamineus have been published. Chin et al. (2009) reported that methanol leaf extracts of O. Stamineus increased both UGT and GST activity in the diabetic rat liver. An in vitro inhibitory study of $O$. Stamineus on UGT isoforms showed that the extract inhibited UGT1A9, UGT1A1, UGT1A6 and UGT1A8 with an $\mathrm{IC}_{50}$ of $10.83,24.65,30.02$ and $43.39 \mu \mathrm{g} / \mathrm{mL}$, respectively. However, the extract showed an $\mathrm{IC}_{50}$ of more than $50 \mu \mathrm{g} / \mathrm{mL}$ for UGT1A3, UGT1A10, UGT2B7 and UGT2B15 activities (Ismail et al., 2010). Chin and Hussin (2011) reported that O. Stamineus increased aminopyrine metabolism by inhibiting protein kinase- $A$ in female rat hepatocytes.

The use of herbal remedies that are often coadministered with prescribed drugs has led to an increase in herb-drug interactions (Zhou et al., 2004). These herb-drug interactions have a high prevalence but are often unknown, which signifies negligence of consumers with regard to reporting herb-drug interactions or adverse reactions when taking herbal medicines (Barnes et al., 1998). There are many reports that provide evidence for clinically important herb-drug interactions, where the concurrent use of herbal medicines with synthetic drugs is noted (Fugh-Berman, 2000).

The herb-drug interactions may occur with the use of $O$. stamineus and prescribed drugs since 
the herb is commonly used to treat diabetes mellitus, hypertension and gout problems in many Southeast Asia countries (Wiart, 2002). The interaction may occur during the pharmacokinetic phase, which includes absorption, distribution, metabolism or excretion processes, and also in the pharmacodynamic phases (Izzo et al., 2002). Alteration of drug concentrations by the concurrent use of herbal medicines may occur through the inhibition or induction of hepatic drug-metabolizing enzymes, especially the cytochrome P450s (CYP) (Wilkinson, 1997; Ioannides, 2002; Zhou et al., 2003). The aim of this study was to examine the effect of $O$. stamineus on the activities of human CYP450 isoforms, especially CYP1A2, CYP2C9, CYP2D6 and CYP3A4.

\section{MATERIALS AND METHODS Reagents}

The luminescence assay was performed according to Hanapi et al. (2010), using a 96well microtiter plate using the P450-GLOTM Screening System from Promega ${ }^{\circledR}$, USA (Thermo Scientific ${ }^{\circledR}$, Finland). The screening systems included the four sub-types of CYP450 (CYP 1A2, 2C9, 2D6 and 3A4) and 4 different substrates were used in these experiments: luciferin 6' methyl ether (luciferin-ME) for CYP1A2 and 6' deoxyluciferin (luciferin-H) for CYP2C9, and the ethylene glycol ester of luciferin 6' methyl ether (luciferin-H EGE) and luciferin 6' benzyl ether (luciferin-BE) for CYP2D6 and CYP3A4, respectively. Each system contained the luciferin detection reagent, the CYP membranes and control membranes, the solution $\mathrm{A}$ and $\mathrm{B}$ of the $\mathrm{NADPH}$ regeneration system, $1 \mathrm{M}$ potassium phosphate buffer and luciferin-free water. Four known positive controls, sulfaphenazole, alpha naphtoflavone, quinidine and ketoconazole, were purchased from Sigma Chemicals, MO, USA.

\section{Plant materials}

The O. stamineus extract was provided by Prof. Zhari Ismail from the School of Pharmaceutical Sciences, Universiti Sains Malaysia. The extract was obtained according to the previous study. O. stamineus leaves were collected in the afternoon, from plants aged 30 to 45 days, white flowered plants and the voucher specimens of plant material were deposited at Bilik Herba, School of
Pharmaceutical Sciences, Universiti Sains Malaysia. Methanol extraction of O. stamineus was performed by extracting the dried leaves $(10 \mathrm{~g})$ with $100 \mathrm{~mL}$ of methanol at approximately $40^{\circ} \mathrm{C}$ for 4 hours with continuous stirring. The extract was filtered through Whatman filter paper (No. 1), and then concentrated and spray-dried to obtain the crude methanol extract (Akowuah et al., 2004).

\section{Luciferin standard curve preparation}

Luciferin standard curve of each CYP was performed by preparing the D-luciferin stock solutions at concentration of $2 \mathrm{mM}$. Then, a serial dilution concentration of D-luciferin standard (four times concentration) was made to obtain the standard solutions with final concentrations of $2 \mu \mathrm{M}, 0.4 \mu \mathrm{M}, 0.08 \mu \mathrm{M}$ and $0.016 \mu \mathrm{M}$. The reaction mixture and reaction control mixture for each CYP (CYP1A2, CYP3A4, CYP2C9 or CYP2D6) were prepared at four times concentrations, while the NADPH regeneration system was prepared at a two times concentration. The reaction was started by adding $12.5 \mu \mathrm{L}$ of D-luciferin standards into a 96-well white opaque plate in the appropriate wells; in the $0 \mu \mathrm{M}$ D-luciferin wells, $12.5 \mu \mathrm{L}$ of luciferin-free water was added. The control reaction mixture $(12.5 \mu \mathrm{L})$ was then added and the plate was shaken by tapping the plate carefully. The reaction system was preincubated for $10 \mathrm{~min}$ at $27^{\circ} \mathrm{C}$ and $25 \mu \mathrm{L}$ of CYP $\mathrm{NADPH}$ regeneration system was added to each well. The plate was tapped again and incubated for $30 \mathrm{~min}$ at $27^{\circ} \mathrm{C}$. The reconstituted luciferin detection reagent $(50 \mu \mathrm{L})$ was added to all of the wells, was briefly mixed and then incubated for $20 \mathrm{~min}$ at $27^{\circ} \mathrm{C}$ to stabilize the luminescent signal. The signal was recorded using a plate-reading luminometer (Hidex Plate CHAMELEON $^{\circledR}$, Hidex Oy, USA) and the values were displayed as relative light units (RLU).

\section{Enzyme assay}

The enzyme assay was performed by adding the test compound of $O$. stamineus solution $(12.5 \mu \mathrm{L})$ with concentrations ranging from 0.01 to $1000 \mu \mathrm{g} / \mathrm{mL}$ or the positive control solution ranging from 0.02 to $200 \mu \mathrm{M}$ to the wells of a microtiter plate. In the untreated wells, the test compound was replaced with the 


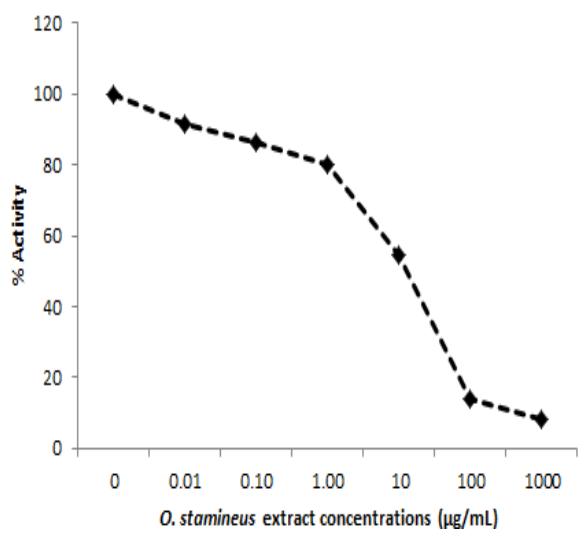

A



B

Figure 1. Effect of O. stamineus (A) and Sulphaphenazole (B) on the CYP2C9 activity.

$12.5 \mu \mathrm{L}$ of luciferin-free water. Then, $12.5 \mu \mathrm{L}$ of the control reaction mixture was added and the reaction was continued as described in section "luciferin standard curve preparation".

\section{Data analysis}

The data are presented as percentage of activity compared to the blank group and the $\mathrm{IC}_{50}$ was determined to examine the inhibitory potency of $O$. stamineus extract and the positive control on cytochrome P450 enzyme activity.

\section{RESULTS AND DISCUSSION}

This interaction study used four human CYP450 isoforms namely CYP1A2, CYP3A4, CYP2D6 and CYP2C9 to examine the effect of O. stamineus and positive control on the enzyme activities using a luminescent assay. Alpha naphtoflavone, ketoconazole, quinidine and sulphaphenazole were used as positive control towards CYP1A2, CYP3A4, CYP2D6 and CYP2C9, respectively. In this assay, beetle luciferin was taken as a luminogenic P450 probe substrates. Beetle luciferin would be converted by different P450 enzymes to luciferin. Then, the luciferase enzyme will create light from the free luciferin as a substrate and supported by ATP and oxygen. The light produced is directly proportional to the activity of CYP450 enzyme and was measured using a microplate reader. Luminescent assay is more profitable as compared to the fluorescent assay, because there has no fluorescent interferences (Bosetti et al., 2005)
Interaction results of $O$. stamineus and the positive control towards four CYP450 isoforms are shown in Figure 1-4, while the $\mathrm{IC}_{50}$ results are shown in Table I. The methanol extract of $O$. stamineus showed an inhibitory effect on CYP450 activities, with the highest inhibition towards CYP2C9 and has an $\mathrm{IC}_{50}$ at $20.12 \mu \mathrm{g} / \mathrm{mL}$. The $O$. stamineus's $\mathrm{IC}_{50}$ was greater if compared to sulphapenazole as positive control with an $\mathrm{IC}_{50}$ at $0.03 \mu \mathrm{g} / \mathrm{mL}$ (Figure 1). The same phenomena were also found in the interaction results of $O$. stamineus extract towards CYP1A2, CYP2D6 and CYP2C9 activities with $\mathrm{IC}_{50}$ values of $49.90 \mu \mathrm{g} / \mathrm{mL}$, $89.24 \mu \mathrm{g} / \mathrm{mL}$ and $97.82 \mu \mathrm{g} / \mathrm{mL}$, respectively. The positive control showed the $\mathrm{IC}_{50}$ values of $0.007 \mu \mathrm{g} / \mathrm{mL}, \quad 2.9 \mu \mathrm{g} / \mathrm{mL}$ and $0.003 \mu \mathrm{g} / \mathrm{mL}$, correspondingly (Figure 2-4). These findings suggest that these plants showed a weak inhibition compared to the positive control. This may because the extract contained many compounds so that the interaction with each CYP450 was not specific.

The O. stamineus extract was reported to possess rosmarinic acid as the main component, with concentrations ranging from $5.1 \%$ to $29.9 \%$ of the total dry leaf weight; also, this extract contained 3'-hydroxy-5, 6, 7, 4'tetramethoxyflavone, eupatorin and sinensetin, with levels ranging from $0.05 \%$ to $0.69 \%$, $0.34 \%$ to $3.37 \%$ and $0.22 \%$ to $1.76 \%$, respectively. Thus, it has great potential for commercialization due to the high medicinal value (Akhouwah et al., 2004; Chin \& Hussin, 2011). 

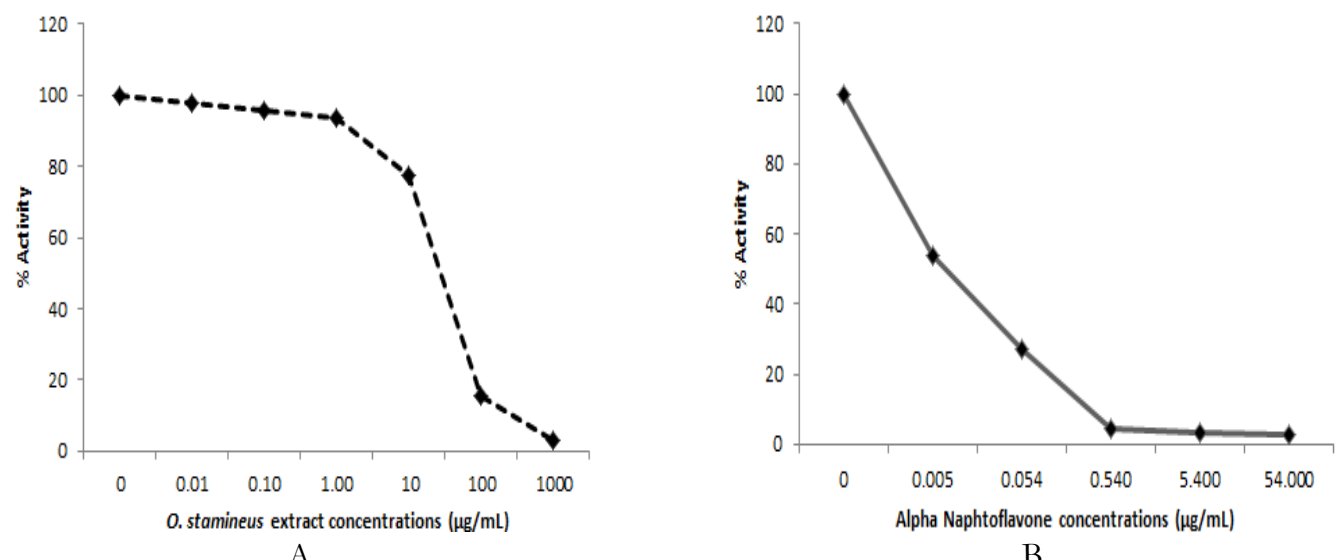

Figure 2. Effect of O. stamineus (A) and Alpha Naphtoflavone (B) on the CYP1A2 activity.
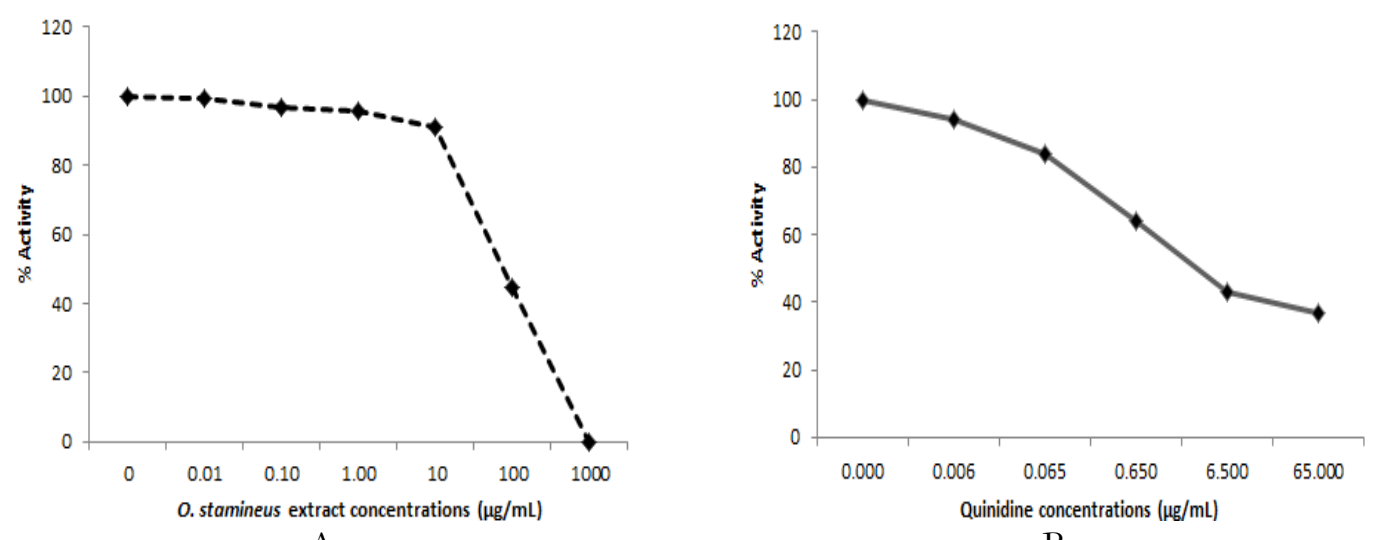

B

Figure 3. Effect of O. stamineus (A) and Quinidine (B) on the CYP2D6 activity

Interactions between herbal remedies and CYP isoforms (CYPs) have been assessed and a number of studies have been published. For example, the inhibitory effects of asiaticoside and madecassoside on human CYPs were studied by Winitthana et al. (2011). The results showed that asiaticoside inhibited CYP2C19 and CYP3A4. Madecassoside also inhibited CYP2C19 and CYP3A4, but both asiaticoside and madecassoside had no effect on the activities of CYP1A2, CYP2C9 and CYP2D6 and CYP2E1. Ohnishi et al. (2000) reported the effect of furanocoumarin derivatives in grapefruit juice on the activity of cytochrome P450 3A4; dihydroxybergamottin, bergamottin and bergapten showed potent inhibition with $\mathrm{IC}_{50}$ ranging from 0.075 to 1.0 $\mu \mathrm{M}$. In another study, the effects of St John's wort (Hypericum perforatum) on human cytochrome P450 activity were investigated by Wang et al. (2001); the results indicated that St John's wort was a selective inductor for CYP3A, but did not alter the CYP1A2, CYP2C9 and CYP2D6 activities after St John's wort was administered.

There are a lot of medicinal plants that have been used either in primary forms or combined into mixtures as traditional medicines. Traditional medicine has been assumed to be non-toxic because the compounds originate from natural sources (Zhou et al., 2004). Pharmacologically active constituents such as alkaloids, flavonoids, terpenoids, polyphenols, anthraquinones, glycosides, saponins, coumarins, tannins and essential oils can be found in plants and have the ability to promote herb-drug interactions (Zhou et al., 2004; Markowitz et al., 2000). 

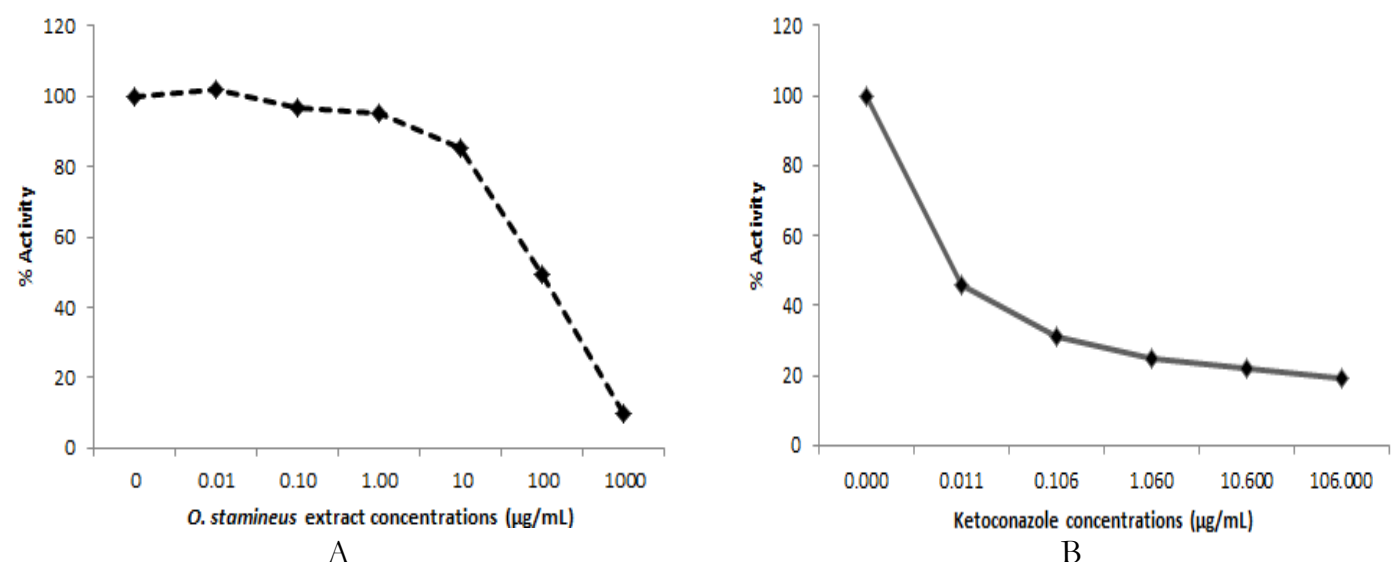

Figure 4. Effect of O. stamineus (A) and Ketoconazole (B) on the CYP3A4 activity

Table I. IC $\mathrm{C}_{50}$ values of $\mathrm{O}$. stamineus extract and positive control after interaction with the four human CYP isoforms

\begin{tabular}{ccc}
\hline \multirow{2}{*}{ CYP Isoforms } & \multicolumn{2}{c}{ IC $_{50}$ Values } \\
\cline { 2 - 3 } & Positive control IC Stamineus $_{\mathbf{5}}$ & $20.12 \mu \mathrm{g} / \mathrm{mL}$ \\
CYP2C & Sulphaphenazole $-0.03 \mu \mathrm{g} / \mathrm{mL}$ & $49.90 \mu \mathrm{g} / \mathrm{mL}$ \\
CYP1A2 & Alpha Naphtoflavone $-0.007 \mu \mathrm{g} / \mathrm{mL}$ & $89.24 \mu \mathrm{g} / \mathrm{mL}$ \\
CYP2D6 & Quinidine $-2.9 \mu \mathrm{g} / \mathrm{mL}$ & $97.82 \mu \mathrm{g} / \mathrm{mL}$ \\
CYP3A4 & Ketoconazole $-0.003 \mu \mathrm{g} / \mathrm{mL}$ & \\
\hline
\end{tabular}

Intestinal $\mathrm{PgP}$ and CYP3A4 have an important role in determining many drugs' bioavailability. The modulation of CYP3A and intestinal $\mathrm{PgP}$ constitutes an important mechanism of increasing or decreasing the concomitant drug bioavailability (FughBerman, 2000; Fugh-Berman and Ernst, 2001; Izzo and Ernst, 2001). The interaction of $O$ stamineus extract with CYP2C9 and CYP1A2 induced moderate inhibition towards the two CYPs (Qiu et al., 2008), suggesting that the extract may modulate the metabolism of drugs metabolized by CYP2C9 and CYP1A2. It has been estimated that CYP2C9 is responsible for the metabolic clearance of up to $15-20 \%$ of all drugs undergoing phase I metabolism (Booven et al., 2010), while the cytochrome CYP1A2 plays a major role in the metabolism of many drugs that commonly clinical used (5-10\%).

\section{CONCLUSION}

The standardized extract of $O$. stamineus showed moderate inhibition towards CYP2C9 and CYP1A2 with $\mathrm{IC}_{50}$ values of $20.12 \mu \mathrm{g} / \mathrm{mL}$ and $49.90 \mu \mathrm{g} / \mathrm{mL}$. While interaction study with
CYP2D6 and CYP3A4 showed inhibition with $\mathrm{IC}_{50}$ values of 89.24 and $97.82 \mu \mathrm{g} / \mathrm{mL}$, respectively. These data suggested that $O$. stamineus extract may induce herb-drug interactions, since the CYP2C9 or CYP1A2 isoforms are responsible for the metabolism of many drugs.

\section{ACKNOWLEDGEMENT}

The authors wish to acknowledge to Prof. Zhari Ismail from School of Pharmaceutical Sciences, Universiti Sains Malaysia who provided the extract for this research project.

\section{REFERENCES}

Akowuah GA., Zhari, I., Norhayati I., Sadikun A., Khamsah SM. 2004. Sinensitin, eupatorin, 3'-hydroxy-5, 6, 7, 4'tetramethoxyflavone and rosmarinic acid contents and antioxidative effect of Orthosiphon stamineus from Malaysia. Food Chem. 82: 559-566.

Barnes J., Mills SY., Abbot NC., Willoughby M., Ernst E.1998. Different standards 
for reporting ADRs to herbal remedies and conventional OTC medicines: faceto-face interviews with 515 users of herbal remedies. Br. J. Clin. Pharmacol. 45: 496-500.

Booven DV., Marsh S., McLeod H., Carrillo MW., Sangkuhl K., Klein TE., Altman RB. 2010. Cytochrome P450 2C9CYP2C9. Pharmacogenet Genomics. 20(4): 277-281.

Bosetti A., Sobol M., Ma D., Good T., Liu D., Cali JJ. 2005. Bioluminescent ytochrome P450 assays. Pharmacology. 3: 9-18.

Chin JH., Hussin AH., Ismail S. 2009. Effect of Orthosiphon Stamineus Leaf Extracts On Hepatic Cytochrome P450, UGT And GST Activity In STZ-Induced Diabetic Rats. J.Adv. Scie.Arts. 1(1): 1-8.

Chin JH., Hussin AH. 2011. Orthosiphon Stamineus Increases metabolism of Aminopyrine in Female Rat Hepatocytes by Inhibiting Protein Kinase-A. Int. J. Pharm. Sci. Res. 2(7): 1777-1780.

Fugh-Berman A. 2000. Herb-drug interactions. Lancet. 355: 134-138.

Fugh-Berman A., Ernst E. 2001. Herb-drug interactions: review and assessment of report reliability. Br. J. Clin. Pharmacol. 52: 587-595.

Hanapi NA., Azizi J., Ismail S., Mansor SM. 2010. Evaluation of selected Malaysian medicinal plants on phase I drug metabolizing enzymes, CYP2C9, CYP2D6 and CYP3A4 activities in vitro. Int. J. Pharm. 6(4): 494-499.

Indubala J., Ng LT. 2000. Herbs: The Green Pharmacy of Malaysia $1^{\text {st }}$ ed. Vinpress Sdn. Bhd., Kuala Lumpur, pp.76.

Ioannides C. 2002. Xenobiotic Metabolis: an Overview. In C. Ioannides (Ed.), Ensymes Systems The Metabolise Drugs and Other Xenobiotics. John Wiley \& Sons, Ltd., West Sussex, pp. 1-30.

Ismail S., Hanapi NA., Halim MRA., Uchaipichat V., Mackenzie PI. 2010. Effects of Andrographis paniculata and Orthosiphon stamineus extracts on the glucuronidation of 4methylumbelliferone in human UGT isoforms. Molecules. 15: 3578-3592.
Izzo AA., Ernst E. 2001. Interactions between herbal medicines and prescribed drugs: a systematic review. Drugs. 61(15): 21632175.

Izzo AA., Borrelli F., Capasso R. 2002. Herbal medicine: the dangers of drug interaction. Trends Pharmacol. Sci. 23: 358359.

Markowitz JS, de Vane CL., Boulton DW., Carson SW., Nahaz Z., Risch SC. 2000. Effect of St. John's wort (Hypericum perforatum) on cytochrome P-450 2D6 and 3A4 activity in healthy volunteers. Life Sci. 66: 33-39.

Ohnishi A., Matsuo H., Yamada S., Takanaga H., Morimoto S., Shoyama Y., Ohtani H., Sawada Y. 2000. Effect of furanocoumarin derivatives in grapefruit juice on the uptake of vinblastine by Caco-2 cells and on the activity of cytochrome P450 3A4. Br. J. Pharmacol. 130: 1369-1377.

Pietta P., Simonetti P., Mauri P. 1998. Anioxidant activity of selected medicinal plants. J. Agric. Food Chem. 46: 44874490.

Qiu F., Zhang R., Sun J., Jiye A., Hao H., Peng Y., Ai H., Wang G. 2008. Inhibitory Effects of Seven Components of Danshen Extract on Catalytic Activity of Cytochrome P450 Enzyme in Human Liver Microsomes. Drug Metab. Dispos. 36(7): 1308-1314.

Sumaryono, W., Proksc, P., Wray, V., Witte, L., and Hartmann, T. 1991. Qualitative and quantitative analysis of the phenolic constituents from Orthosiphon aristatus. Planta Med. 57: 176-180.

Tezuka Y., Stampoulis P., Banskota AJ., Awale S., Kadota S., Saiki I. 2000. Constituents of the Vietnamese medicinal plant Orthosiphon stamineus. Chem. Pharm. Bull. 48: 1711-1719.

Wang Z., Gorski JC., Hamman MA., Huang SM., Lesko LJ., Hall SD. 2001. The effects of St John's wort (Hypericum perforatum) on human cytochrome 450 activity. Clin. Pharmacol. Ther. 70: $317-$ 326

Wiart C. 2002. Orthosiphon stamineus, Benth. In: F. K. WONG (Ed.). Medicinal plants of 
Southeast Asia. Prentice Hall, Selangor, pp. 264.

Wilkinson GR. 1997. The effects of diet, aging and disease-states on presystemic elimination and oral drug bioavailability in humans. Adv. Drug Deliv. Rev. 27: 129159.

Winitthana T., Niwattisaiwong N., Patarapanich C., Tantisira MH., Lawanprasert S. 2011. In vitro inhibitory effects of asiaticoside and madecassoside on human cytochrome P450. Toxicology in vitro. 25 (4): 890-896.

Zhou SF., Gao YH., Wen QJ., Huang M., Xu AL., Paxton JW. 2003. Interactions of herbs with cytochrome P450. Drug Metab. Rev. 35: 35-98.

Zhou S., Koh HL., Gao Y., Gong Z., Lee EJD. 2004. Herbal bioactivation: The good, the bad and the ugly. Life Sci. 74: 935968. 